\title{
Chylothorax: diagnosis by lipoprotein electrophoresis of serum and pleural fluid
}

\author{
NATHAN S. SERIFF, MICHAEL L. COHEN, PAUL SAMUEL, AND PAUL L. SCHULSTER
}

From the Division of Pulmonary Medicine and the Lipid Research Laboratory of the Department of Medicine, The Queens Hospital Center Affiliation of the Long Island Jewish-Hillside Medical Center New York City, New York, and the School of Medicine, Health Sciences Center, State University of ? New York at Stony Brook

Seriff, N. S., Cohen, M. L., Samuel, P., and Schulster, P. L. (1977). Thorax, 32, 98-100. Chylothorax: diagnosis by lipoprotein electrophoresis of serum and pleural fluid. This report describes a 31-year-old woman who underwent a technically difficult left pneumonectomy for tuberculosis and developed thereafter a large leît pleural effusion which was milky in colour. A traumatic chylothorax was suspected, and the diagnosis was confirmed by simultaneous fasting pleural and serum lipid studies and lipoprotein electrophoresis. The latter study was especially helpful in confirming the chylous nature of the fluid in that it revealed a marked chylomicron band at the origin; this was not present in the patient's serum nor in the pleural fluid of five patients with other disease states studied as controls.

The diagnosis of chylothorax is usually suspected when milky fluid is removed at thoracentesis. Another entity, however, the pseudochylous pleural effusion, may be indistinguishable in appearance. It consists of a cholesterol-rich fluid with low or absent triglycerides which results from chronic pleural infection or inflammation (Roy et al., 1967). The presence of fat globules stained by Sudan dyes on microscopic examinations of milky pleural fluid was thought to confirm the diagnosis of chylothorax. However, this has been shown to be incorrect by Denborough and Nestel (1964). It appears, therefore, that only chemical analysis of the precise lipid composition of milky effusions can confirm their nature as truly chylous.

Chylothorax may arise spontaneously and without apparent cause, may occur as a result of malignancies of the lung and mediastinum, or may follow blunt or penetrating chest trauma (Bessone et al., 1971; MacFarlane and Holman, 1972). Chylous pleural effusions may also result from various thoracic surgical procedures. Since the thoracic duct crosses to the left of the spine between the fifth and seventh thoracic vertebrae, it is especially vulnerable to traumatic injuries during operation on the left hemithorax near the hilum, including procedures on the heart and great vessels, and resections of the oesophagus and left lung (Goorwitch, 1955; Selle et al., 1973). This report describes a young patient who developed a milk@ left pleural effusion after a difficult left pneumor $\vec{B}$ ectomy for tuberculosis, and in whom simuF. taneous fasting serum and pleural fluid lipid an lipoprotein electrophoretic studies proved of value in confirming the chylous nature of the fluid.

\section{Case report}

A 31-year-old black woman was first discovere d to have active tuberculosis of the left upper lobe lingula, and left lower lobe in February 1969. She was at that time admitted to the Tuberculosis Section of the Division of Pulmonary Medicine this institution for treatment. After a brief spel in hospital she was discharged on isoniazid arfs ethambutol, but failed to take the tablets regularly, Her sputum again became positive with radi\& graphic progression and she was readmitted frip September 1969. After a period of sputum conversion accomplished with rifampicin aft pyrizinamide, her sputum became positive aga and remained positive thereafter. A left pneumonectomy was therefore carried out on 17 Octobgr 1973. It was a technically difficult operatio requiring an extrapleural dissection over the upper lobe and lingula. No drainage tube was used post operatively.

By the tenth postoperative day, although the 
patient was free of symptoms, fluid was seen to be oozing from the surgical incision. Thoracentesis revealed milky fluid, and a traumatic pos toperative chylothorax was diagnosed. The fluid rapidly reaccumulated, and it was considered to be important to confirm the diagnosis as simply and expeditiously as possible.

To attempt a biochemical diagnosis, pleural fluid and serum were simultaneously examined with the patient in the fasting state for (1) cholesterol, (2) triglycerides, and (3) lipoproteins by electrophoresis (Abell et al., 1952; Fredrickson and Lees, 1966; Van Handel and Zilversmit, 1957). The results of the cholesterol and triglyceride determinations are noted below:

$\begin{array}{lll}\text { Cholesterol } & \text { Serum } & \text { Pleural fluid } \\ & 175 \mathrm{mg} / 100 \mathrm{ml} & 96 \mathrm{mg} / 100 \mathrm{ml} \\ & (4.5 \mathrm{mmol} / \mathrm{l}) & (2.5 \mathrm{mmol} / \mathrm{l}) \\ \text { Triglycerides } & & \\ & 75 \mathrm{mg} / 100 \mathrm{ml} & 538 \mathrm{mg} / 100 \mathrm{ml} \\ & (0.64 \mathrm{mmol} / \mathrm{l}) & (6.1 \mathrm{mmol} / \mathrm{l})\end{array}$

The Figure shows the simultaneously determined lipoprotein electrophoresis patterns in serum and pleural fluid.

These studies revealed that the serum was clear and that both its lipid and lipoprotein electrophoretic patterns were normal. The pleural fluid, however, was lactescent and contained large concentrations of triglycerides. The lipoprosein electrophoretic pattern of the pleural fluid showed a marked chylomicron band at the origin, indicating the chylous nature of the pleural fluid.

In an attempt to ascertain the specificity of these lipid studies for chylous effusions, pleural fluid was obtained for study from five other patients with non-milky pleural effusions. Three had tuberculous effusions and two had bacterial empyemas. The mean pleural fluid cholesterol was $72 \mathrm{mg} / 100 \mathrm{ml}(1.9 \mathrm{mmol} / \mathrm{l})$ in these five patients (range $54-83 \mathrm{mg} / 100 \mathrm{ml}(1 \cdot 4-2 \cdot 1 \mathrm{mmol} / \mathrm{l})$ ). Their mean triglyceride concentration was $19 \mathrm{mg} / 100 \mathrm{ml}$ $(0 \cdot 2 \mathrm{mmol} / \mathrm{l}$ ) (range $10-27 \mathrm{mg} / 100 \mathrm{ml}(0 \cdot 1-0.3$ $\mathrm{mmol} / \mathrm{l})$ ). Finally, on their lipoprotein electrophoresis, only a faint band at the level of beta or pre-beta lipoprotein was seen without any chylomicron band at the origin.

Fortunately, in our patient chyle did not accumulate after the second thoracentesis. The patient steadily improved and was discharged. Six months after discharge her sputum was negative and no evidence of fluid was noted on the chest radiograph. At present, three years after surgery, she is entirely well.

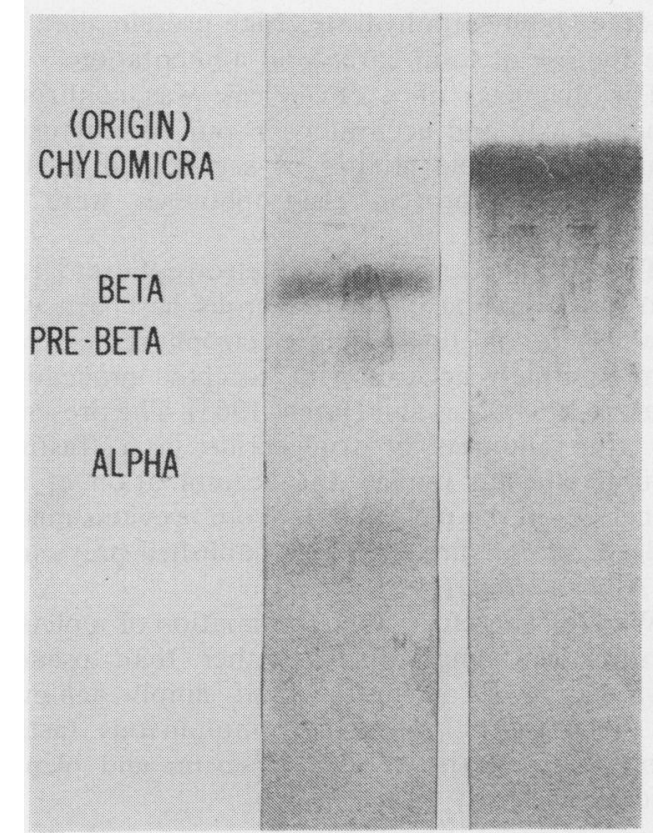

Figure Electrophoretic pattern of serum (left) and pleural fluid (right) lipids. Serum pattern is normal. The pleural fluid reveals a marked chylomicron band.

\section{Comments}

This case illustrates a fortunately rare complication of resectional lung surgery, that is, chylothorax after a difficult left pneumonectomy. The clinical course of our patient is typical of chylothorax following surgical trauma. The rapidity of its development is related to the size of the thoracic duct injury and the dietary intake of fats. Surgical trauma to the thoracic duct usually results in the development of chylothorax on the seventh to 14th postoperative day, while chylothorax develops about six weeks after blunt chest trauma. There is, however, a wide range of times of onset, depending upon the severity of the trauma. It is now believed that patients with postoperative chylothorax will heal with conservative treatment within three to four weeks, that is, without surgical reoperation and repair of the thoracic duct (Randolph and Gross, 1957; Schmidt, 1959). Bessone et al. (1971) recommend that 'all patients with congenital, postoperative, or traumatic chylothorax, in whom immediate thoracotomy for the control of an associated lesion is not required, should be managed by initially conservative methods'. Conservative management includes adequate pleural drainage and a 
fat-free, high-carbohydrate, high-protein diet, or else the use of total parenteral alimentation.

The diagnosis of a chyle leak was confirmed expeditiously and accurately in our patient using simultaneous lipid studies of serum and pleural fluid. The lipoprotein electrophoreses were especially helpful.

That the band noted on the electrophoretogram is truly composed of chylomicrons has been well established, and lipoprotein electrophoresis is now done routinely according to accepted procedures (Hatch, 1968; Lees and Hatch, 1963). The presence of large amounts of triglyceride in a 'fasting' pleural effusion implies the accumulation of triglycerides in the pleural fluid from previous meals. Indeed, similar findings were published previously by Albrink et al. (1955).

We feel, therefore, that confimation of a pleural effusion as being chylous rather than pseudochylous can be accurately and simply achieved by lipid studies, especially simultaneous fasting lipoprotein electrophoresis of serum and pleural fluid.

\section{References}

Abell, L. L., Levy, B. B., Brodie, B. B., and Kendall, F. E. (1952). A simplified method for the estimation of total cholesterol in serum and demonstration of its specificity. Journal of Biological Chemistry, 195, 357-366.

Albrink, M. J., Glenn, W. W. L., Peters, J. P., and Man, E. B. (1955). The transport of lipids in chyle. Journal of Clinical Investigation, 34, 1467-1475.

Bessone, L. N., Ferguson, T. B., and Burford, T. H. (1971). Chylothorax. Annals of Thoracic Surgery, 12, 527-550.

Denborough, M. A. and Nestel, P. J. (1964). Milky effusions. Medical Journal of Australia, 2, 874-876.
Fredrickson, D. S. and Lees, R. S. (1966). Familiat" hyperlipoproteinemia. In Metabolic Basis of In herited Disease, edited by J. B. Stanbury, J. B Wyngaarden, and D. S. Fredrickson., 2nd ed McGraw-Hill, New York.

Goorwitch, J. (1955). Traumatic chylothorax ang thoracic duct ligation; case report and review of literature. Journal of Thoracic Surgery, 29, 467? 479.

Hatch, F. T. (1968). Practical methods of plasms lipoprotein analysis. Advances in Lipid Researc 6, 1-68.

Lees, R. S. and Hatch, F. T. (1963). Sharper separatiof of lipoprotein species by paper electrophoresis in albumin-containing buffer. Journal of Laborator $E_{0}$ and Clinical Medicine, 61, 518-528.

MacFarlane, J. R. and Holman, C. W. (1972). Chylo thorax. American Review of Respiratory Disease $\vec{e}$ 105, 287-291.

Randolph, J. G. and Gross, R. E. (1957). Congenita chylothorax. Archives of Surgery, 74, 405-419.

Roy, P. H., Carr, D. T., and Payne, W. S. (1967). The problem of chylothorax. Mayo Clinic Prä ceedings, 42, 457-467.

Schmidt, A. A. (1959). Chylothorax, review of five years' cases in the literature and report of a case Acta Chirurgica Scandinavica, 118, 5-12.

Selle, J. G., Snyder, W. H., 3rd, and Schreiber, J. $\frac{6}{6}$ (1973). Chylothorax: Indications for surgery. Anna of Surgery, 117, 245-249.

Van Handel E., and Zilversmit, D. B. (1957). Micre method for the direct determination of serun triglycerides. Journal of Laboratory and Clinicat Medicine, 50, 152-157.

Requests for reprints to Dr. Nathan S. Seriff, Directo Division of Pulmonary Medicine, Queens Hospitald Center, Queens, New York 11432, USA. 